\title{
Conceptual Model of Adult Education Development in the USA and Canada
}

\author{
O. O. Terenko
}

Sumy State pedagogical University named after A. S. Makarenko

Corresponding author. E-mail: eterenko@ukr.net

Paper received 05.08.19; Accepted for publication 22.08.19.

\author{
https://doi.org/10.31174/SEND-PP2019-202VII82-12
}

\begin{abstract}
The article deals with conceptual model of adult education in the USA and Canada. The concept "learning organization" is analysed. Key technologies that are used for creation of learning oraganisation are singled out. Term "corporate university" is viewed. Types of corporate university are systematized. Peculiarities of corporate training are analysed. Concept "third age university" is researched. Necessity of third age university establishment is substantiated. Key features of third age university are pointed out. Educational process at third age university is viewed.
\end{abstract}

Keywords: adult education, USA, Canada, learning organization, third age university.

Introduction. In Canada and the USA, as in most Western countries, attention to issues of informal adult education was especially aggravated in the 70 years of the XX due to debate about the global crisis in the sphere of education. The task of informal education was to offset the shortcomings of formal education (school, vocational and higher), the rapid and timely provision of educational opportunities to all who are in need.

For this reason, the importance of informal education in Canada and the USA has become apparent since the existing forms of traditional education have not been able to meet the growing diversity of cognitive requests of various strata of population. This is particularly true of adults who wish to continue their education, but because of the daily employment, diversity of interests and other reasons require flexible organizational forms of educational activity.

Analysis of literature. Diverse aspects of adult education were researched by American and Canadian scientists. Adult education as a phenomenon was discovered by Darkenwald G., Lindeman E., Knowles M. Procedural aspects of adult education were discovered by Cross P., Heckhausen H., Herzberg F. Conetent peculiarities of adult education are disclosed in works of such scientists as McClelland C. and McGregor D.

Aim of the article. The aim of the article is to analyse conceptual model of adult education development in the USA and Canada.

Materials and methods. New forms of informal adult education, which have become widespread since the second half of the XX century, are learning organizations and universities of the third age.

The concept of a "learning organization" pedagogy appeared in Canada and the USA in the $80^{\text {th }}$ of the XX century. Fairly short and capacious definition of learning organization is the following "learning organization - an organization that promotes education of its members and is in the process of self-perfection". A more detailed definition is the following: organization that learns continuously and transforms itself. Training takes place at the level of individuals, in teams throughout the organization, and even communities with which the organization interacts. Learning is a continuous process that is used strategically - integrated into the work [5].

The ability to see properly and understand the enterprise generally refers to key concepts of learning organization, which, is interaction between individual compo- nents of the organization and external environment for the benefit of particular organization as an integrated system. The learners are characterized by full involvement of employees in the process of jointly initiated changes that have collective responsibility and are focused on common values and principles.

While determining basic principles of the concept of learning organization it is necessary to single out key points of business transformation in the organization. According to the views of Maslow A., members of the organization must learn five key technologies, leading to the creation of learning organization:

changing the outlook of participants, their common "mental attitudes" from seeing parts to seeing the whole, people from consideration as recipients to their understanding as active participants in what is happening;

- $\quad$ improving personal skills;

- changing mental models;

- construction of general strategy shared by all participants;

participating in training in teams [11].

Another American author Mc Gregor D., emphasizes collective, team-building nature of organizational learning, importance of developing common content for all participants. According to the scientist, there must be a dialogue between members of organization. This collective sense, that is the norm, strategy and starting position of the organization's functioning, serves as the core, which holds together, "glues" all business. Mc Gregor D. identifies seven key principles that characterize a new type of study: reliance on discussion, not speech; equal participation; encouraging multiple viewpoints; dialogue that does not have scientific justification; usage of database, done by the participants; making of overall experience that is shared by all team members; making conditions that are suitable for unexpected results (this component aims at moveing away from areas of known and previously non-existent search capabilities of object) [13].

There are six imperatives of action that are required for their construction and operation. The first imperative is to create and support continuing education opportunities at all levels of the organization. The range of possibilities extends from the prediction of favorable conditions for learning in the workplace to organizeing of global interactive commands, transformation learning into an integral part of every working day. There are other imperatives that are important for building learning organization: 
research and dialogue, cooperation and training in teams of organizational capacity for new thinking, which then becomes the property of collective vision and its interaction with the outside world. The last imperative recognizes the importance of enterprise communication with clients, its work at various levels - local, national, international and its impact on the organization. These connections are symbiotic in nature, interdependence and mutual benefit.

Founding organizations' learners is essential for systematic training at job, because they are considered in Canadian and American management as a key to increase of productivity and thus ensuring competitiveness in the world market. In order to attract private and public institutions to organizational learning in 1995 by support of the Center for Public Management Canadian Canadian Sonsortium for Organizational Learning was founded.

Traditional set of training programs often is replaced by a broader approach to the practice of inner training, called "corporate university".

Corporate university is considered as development of content, forms and methods of corporate training; training of effective working methods; possession of specific training tools for adequate solution of emerging problems; the introduction of common business technologies at all levels of the organization and their constant updating; formation of common corporate values and a common language of communication, development of modern corporate culture; building a permanent internal communications to explain management decisions from the top to down [1].

There are two models of corporate university. According to the first model, company enters into contracts with universities and / or consulting firms that already exist. In this case, the school provides facilities, specialists, teachers, and counselors develop curriculum. A substantial role in learning professionals belongs to domestic companies that provide personnel information on those subjects that are not taught in traditional educational institutions and bring into the classroom "reality".

According to the second model, university is a unit that is directly involved in the organization of the educational process. The primary task of this unit is to formulate the curriculum for the organization as a whole, development of specialized training programs for individual departments or programs designated for specific projects. The curriculum usually combines various forms of training, seminars and lectures, business training, independent work using educational video courses, distance learning. Effectiveness of corporate universities is determined by a number of fundamental characteristics: systematic approach, the continuity of learning prevalence at all levels of management of the organization, taking into account the specific characteristics of a particular business.

Third age universities are not universities in the traditional sense, for they are an educational organization for people of retirement age, which unites people in groups according to interests and makes it possible, on the one hand, to share their experience, knowledge and skills, and on the other - to learn other participants and to supplement their education [2].

The emergence of these universities is explained by progressive aging of Canadian and American nations and has broad educational impact. However, the first thorough study of these schools showed that "universities of the third age is more a product of" local initiative ", decisive actions of specific individuals, and not the result of deep reflection and planning. In reality, the founders of these institutions have become active university professors or professors, who are retired and looking for new forms of activity for themselves, social workers interested in expanding leisure senior citizens, politicians, to ask election victory, and ordinary citizens elderly - members of social clubs and organizations.

Since the quality of education in the universities of the third age caused some doubts related to them. As a rule, studying in such institutions consisted of random lectures, discussion seminars and courses that students choose without any restrictions or requirements examination - for the purpose of this study was not a university degree. The educational activity was devoid of structure and focused on variety and entertainment. Establishing clear framework content of courses and programs of universities prevented rather heterogeneous target audience as socalled "active senior" different from each other for reasons of health, gender, education preconditions, social and financial situation [14].

Basic principles underlying the work with the elderly in universities of the third age are: student is a person who seeks self-fulfillment, independence, and self-conscious; old man has wisdom, social, professional and personal competence; old man learns to solve important life problems and achieve specific objectives; form of the study - a joint activity of student and teacher at all stages: planning, implementation, evaluation, correction; the one who teaches, serves as a mentor, consultant, facilitator that helps adult student.

Key features of universities of the third age, which differ significantly from traditional education:

prevention, providing preventive measures for blocking and exclusion of risk factors, possible or predictable circumstances, and preparation for old age;

help for older people in acquiring knowledge for independent, productive, daily activities and solving problems;

protection that promotes confrontation or emergence of an active response to possible adverse circumstances, ability to incorporate protective mechanisms based on ones own experience and experience of peers;

compensation, which is designed to compensate for both external and internal factors to ensure the natural aging;

rehabilitation aimed at resumption of older people especially during the transition phase;

integration, providing a transition from isolation, tranquility in the state of cooperation, including useful work in their own interests, the interests of the family, society and the state;

providing interaction between generations, mutual understanding, tolerance, dialogue and integration.

Results and discussion. Nowadays in Canada there are about 1,000 companies that can be classified among the organizations that learn. Pioneers in this field were multinational corporation «NOVA» and the Canadian Imperial Bank of Commerce. 
Training in such organizations is often implemented as a system of inner (corporate) training, training system on the territory of the enterprise involving staff or outside instructors. The aim is to provide corporate training for workers, that is seen as an integral entity of quality of work, characteristic of professional orientation and professional competence.

The specifics of educational work with the staff of enterprise is that all participants (organizers and teachers) are engaged in joint educational activity, for it is "collective subject teaching", that is characterized by the following features: existence of a common goal, which directs the formation of personal and professional competence of participants as a central component of competitiveness; general motivation connected with participants reaching the required level of professional and personal development; integration and coordination of activities of individual members to build a coherent professional development process; selection in cooperative activities of individual actions and functions that implement the task of professional development specialists; coordination of individual actions of stakeholders in order to develop common indicators, enhance professional competence relevant for an employee of a particular company; the result is represented in a combined product - personal and professional competence of an employee who is capable to build a professional career; space and value-orientation unity of the partners that consistently perform individual actions in the whole structure of the educational process. These provisions correspond to the nature of the competence approach, which focuses on the integrity of the formation of core competencies in terms of coordinated activities of the educational process.

The following characteristics help to understand peculiarities of corporate training of specialists: activity defined by constructing vocational education from subjectactive attitude towards public work of forming personality and professional competence; value-orientation unity and cohesion of the group of all participants of educational process; clarity of division of labor, mutual "contribution" and the responsibility of all participants in social activities, providing development of workers' new experience; activities and mutual value-sense communication that help adult learners master the key competencies that form the core of competitiveness; skill development through involvement of each partner of the joint competenceoriented educational activities; ability to provide total product - professionally competent person employee who is competent in solving of professional problems.

Typically, companies are trying to stick to a strategy of personnel development, which consists of two phases: basic training, providing the initial training of new employees; targeted training, which involves periodic measures to improve the professional level of staff training.

Basic training is designed for a wide range of workers and includes seminars on business ethics, maintaining the goodwill and strengthening of corporate culture; training of general organization of work, employees are taught to organize the workplace, plan action with rational use of time, remove barriers the varying complexity; psychological training aimed at effective communication skills that allow to solve conflicts, react adequately in unusual situa- tions, resist stress and maintain good performance. Proper training is necessary for improveing professional level of skilled workers and a high level of specialization. Typically, targeted training programs include a variety of exhibitions, seminars, training, specialized business training, including a program of comprehensive training.

A good example of a typical third age university serves UTA department at Université de Sherbrooke (Université de Sherbrooke) in Canada. The main objective of the university is to provide a process of rehabilitation of older people (over 50 years), as well as ways to enhance their life potential. Graduates are enrolled twice a year: in autumn and winter. Duration of classes is 2-2.5 hours and they are held once a week, the total duration is 25 hours. In order to facilitate access to education for people of the third age, teachers conduct classes not only within the campus, but also in museums, public libraries, churches, etc. Among the most popular subjects are social psychology, literature, biology, history.

The most popular and most successful educational program for seniors in Canada is a university program «Elderhostel»: living together of people of the third age in a hotel for intellectual exchange in a friendly atmosphere. Participants are united by desire to learn something new, to live lives filled with meaning. The educational program consists of one-week course, participants live together and travel, including overseas.

Initiators of the concept of «Elderhostel» were Americans M. Knowlton and D. Bianco, inspired by the atmosphere of society that they met in European tourist centers. Their idea was based on the transfer of this unique atmosphere in environment of elderly people to show them new opportunities for intelligent and productive life in community. Well-built program that combines education, travel and adventure could attract elderly to study and support the process of self-perfection. The first program was implemented in summer of 1975 in the University of New Hampshire, and in 1986 an independent corporation «Elderhostel Canada» was founded,

The task of education is not only a process of adaptation and compensation of loss due to age-related changes as well as special educational culture that generates new look of old - productive, competent, active, full of vitality, experience and wisdom. Participation in a permanent additional education has a positive effect on the overall health of adults and can even be used as a kind of treatment of certain diseases.

Analysis of scientific sources allows to outline a typology of educational courses of Elderhostel Canada, under which are 6 categories of people of retirement age:

1) activity-oriented man - registers only for those programs that involve some form of physical activity: golf, hike, trips for bird watching, etc; the man wants to study in the environment and prefers employment outside of classroom;

2) geography guru - selects a region or city that he wanted to study and explore; for a man Elderhostel Canada program content is not decisive, primarily serving is the opportunity to see and learn new things about the area in which institution is situated;

3) experimenter - a person who participates in Elderhostel programs in Canada for the first time and only begins to describe the range of his interests, registered in 
courses with high levels of physical activity or academic courses if a thorough pre-acquired knowledge in the discipline;

4) adventurer (adventurer) - wants to go anywhere and try anything to get new experience in knowledge despite the accommodative conditions;

5) content-oriented person - agrees to travel anywhere to improve the level of knowledge in a predetermined area, for those students of teaching at the highest university level is a prerequisite for participation in educational programs Elderhostel Canada;

6) average user - a person who is registered on educational courses for specific personal preferences (low prices for accommodation and food, combined with a tour program), the content of training programs in this case is not decisive.

The main factors and assumptions that define the essence of education of the target group are: to provide opportunities for learning and self-development of people of older generation; support physical, psychological and social opportunities for the elderly, to find a new orientation in life, independent and autonomous existence in solving everyday problems; promote dialogue between generations.

Conclusion. Analysis of theory and problems of Canadian and American adult education allows to conclude that learning organization - an organization that promotes education of its members and is in the process of selfperfection. Corporate university is considered as development of content, forms and methods of corporate train- ing; training of effective working methods; possession of specific training tools for adequate solution of emerging problems; the introduction of common business technologies at all levels of the organization and their constant updating; formation of common corporate values and a common language of communication, development of modern corporate culture; building a permanent internal communications to explain management decisions from the top down.

Key technologies, leading to the creation of learning organization: changing the outlook of participants, their common "mental attitudes" from seeing parts to seeing the whole, people from consideration as recipients to their understanding as active participants in what is happening respond to the creation of the future; improving personal skills; changing mental models; construction of general strategy shared by all participants; participating in training in teams. Basic principles underlying the work with the elderly in universities of the third age are: student is a person who seeks self-fulfillment, independence, and selfconscious; old man has wisdom, social, professional and personal competence; old man learns to solve important life problems and achieve specific objectives; form of the study - a joint activity of the student and teacher at all stages: planning, implementation, evaluation, correction; the one who teaches, serves as a mentor, consultant, facilitator that helps adult student.

Future research work will be aimed at analysis of functioning third age universities in European countries.

\section{REFERENCES}

1. Cross, P. Adults as Learners: Increasing Participation and Facilitating Learning. Wiley, 2002. 336 p.

2. Darkenwald, G. G. Adult Education: Foundation of Practice. New York: Harper \& Row, 2012. 260 p.

3. Heckhausen, H. The Anatomy of Achievement Motivation. New York: Academic Press, 2017. 236 p.

4. Herzberg, F. The Motivation to Work. New York: Wiley, 2009. $180 \mathrm{p}$

5. Jarvis, P. Adult Education and Lifelong Learning: Theory and Practice. London: Routledge, 2010. 352 p.

6. Jarvis, P. Adult and Continuing Education. Taylor: Francis, 2003. $432 \mathrm{p}$

7. Kidd, J. Roby. How Adults Learn. New York: Association Press, 2013. 90 p.
8. Knowles, M. Self-directed Learning: A Guide for Learners and Teachers. Toronto: Cambridge Adult Education Company, 2015. $135 \mathrm{p}$.

9. Knowles, M. The Modern Practice of Adult Education. Andragogy Versus Pedagogy. Englewood Cliffs: Prentice Hall, 2017. $400 \mathrm{p}$.

10. Lindeman, E. C. The Meaning of Adult Education. New York, 2009. $143 \mathrm{p}$.

11. Maslow, A. The Maslow Business Reader. Wiley, 2000. 324 p.

12. McClelland, C. Human Motivation. Cambridge: Cambridge University Press, 2017. 663 p.

13. McGregor, D. The Human Side of Enterprise. New York: McGraw-Hill, 2000. 246 p.

14. Vroom, V. Work and Motivation. New York: Wiley, 2014. $397 \mathrm{p}$. 